\title{
Job Insecurity, Work-related Stress and Employee Creativity: Proactive Personality and Team Climate for Innovation as Moderators
}

\author{
Bao-Cheng LIU ${ }^{1, a}$, Mei-Hua SHI ${ }^{2, b, *}$ \\ ${ }^{1}$ Tianjin Foreign Studies University, No.117, Machang Road, Hexi District, Tianjin, China \\ ${ }^{2}$ Macau University of Science and Technology, Avenida Wai Long, Taipa, Macau, China \\ aliubaocheng@hotmail.com, 'btinyshi@126.com \\ *Corresponding author
}

Keywords: Job insecurity, Work-related stress, Employee creativity, Proactive personality, Team climate for innovation.

\begin{abstract}
Nowadays, creativity is vital to enterprises as human capital has become a main competition factor worldwide. Nearly every enterprise wants to have employees with high creativity. Meanwhile, in order to be flexible and quick to adapt to changing environmental needs, organizations frequently downsize which leads to employees' job insecurity. Job insecurity is harmful to employee creativity which has been testified by scholars. Facing this contraction, how to reduce the harmful effect for both employees and enterprises is an urgent question to answer. To this end, the paper introduces proactive personality to employees and team climate for innovation to the enterprises. We developed a cross-level model with moderated mediation in level 1 and a moderator in level 2 . Management implication is also discussed.
\end{abstract}

\section{Introduction}

Creativity in the workplace refers to the ability to product novel and useful ideas by an employee or by a group of employees working together $[1,2,3,4,5]$. From the definition, we know that creativity can be generated by employees in any job and at any level of an organization [6,7]. As creativity is vital for entrepreneurial activities and long-term economic growth [8, 9], scholars have devoted efforts to explore how creativity is ultimately originated [7].

Job insecurity is considered as harmful to the organizations [10], which will lead to stress [11], while stress will harm employee creativity [10]. How to reduce the harmful effect to the least? Do all the employees react the same way when they face stress? These questions lead us to trying to figure out how to reduce the harmful effect to the employees and help the enterprises. After considering many options, we choose two variables: proactive personality and team climate for innovation. Employees with proactive personality are more self-initiated and change-oriented $[12,13]$, and they prefer not to passively wait for information and opportunities to come to them [12, 13, 14]. This variable is used to reduce the negative effect of the mediated effect between job insecurity and employee creativity. For the second variable, we try to introduce culture especially team climate for innovation to our model. Our contribution may lay on introduced a moderated mediation variable and a cross-level moderator.

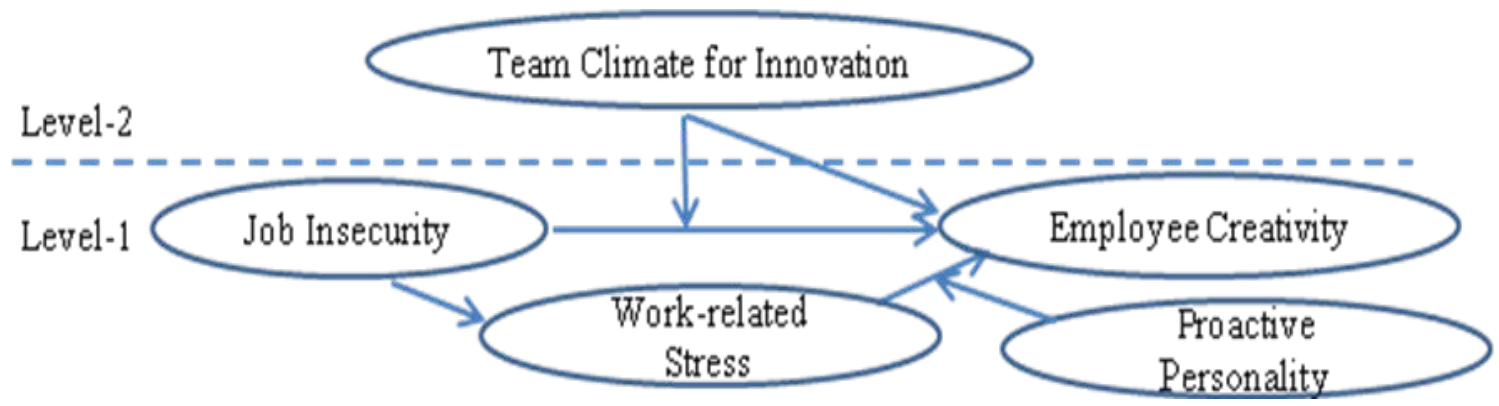

Fig.1 The conceptual model of the paper 


\section{Literature Review and Hypotheses}

\section{Job insecurity and employee creativity}

Job insecurity reflects employees' perceived feeling of threaten, but "perceived powerlessness to maintain desired continuity in a threatened job situation" [15]. According to Greenhalgh and Rosenblatt [15], there are five elements of job insecurity: perceived threat from job features, the importance of job features to employees, perceived threat of the occurrence of various events that would negatively affect an individual's total job, the importance attached to each of those potentialities, and powerlessness. There is an equation of Greenhalgh and Rosenblatt's job insecurity:

Job insecurity $=[(\Sigma$ importance of job loss $\times$ likelihood of losing job feature $)+(\Sigma$ importance of job loss $\times$ likelihood of job loss)] $\times$ perceived powerlessness to resist threat

When felt job security threatened and couldn't deal with it, employees would react differently. Some researchers like Tian and her co-authors [17] found that job insecurity may lead to counterproductive work behavior, others like Probst and his teams [10] found that job insecurity may reduce counterproductive work behavior, but lead to more habitual work [17], for employees would reduce their adventure of challenging the job methods they normally use in order to avoid failure and protect themselves [17]. Regardless of the contradictory findings, we may conclude that job insecurity will harm employee creativity.

Furthermore, in their study, Probst and his co-authors [10] found that "Job insecurity was a significant predictor of creativity scores on the remote associates test $(\beta=-.17, p<.05)$ ", therefore, the results suggested that "greater perceptions of job insecurity were related to lower scores on the creativity test.” Thus we hypothesize:

Hypothesis 1: Job insecurity is negatively related to employee creativity.

\section{Job insecurity and work-related stress}

"Stress is a dynamic condition in which an individual is confronted with an opportunity, demand, or resources related to what the individual desires and for which the outcome is perceived to be both uncertain and important" $[18,19]$. Stress is not all bad in and of itself. According to Cavanaugh and his co-authors [20], there are two kinds of stresses: one is challenge-oriented stress which creates challenges and feelings of fulfillment; the other is hindrance-oriented stress which creates feelings of constrained personal development and work-related accomplishment. Many research findings showed negative context of work-related stress, such as Talbot and his team' s research [21] and Van Dyne and his team's research [11], meanwhile, there are researchers like Stamper and his co-authors [22] found stress' positive value to job performance. Most existing literature generates mix results and inconsistent findings on the relationship between work-related stress and job performance [23].

Job insecurity has become one of the most significant stressors [24]. To Cavanaugh and his co-authors' explanation [20], job insecurity causes hindrance-oriented stress, and hindrance-oriented work-related stress is considered as bad and therefore related negatively to job satisfaction and performance, and positively related to turnover and job search [20]. Employees in job insecurity conditions experience considerable stress, frustration, and anxiety $[25,26]$. Thus, we hypothesize:

Hypothesis 2: Job insecurity is positively related to work-related Stress.

\section{Work-related stress and employee creativity}

What about the relationship between work-related stress and employee creativity? In cognitive resources theory, Vecchio [27] argued that "stressors are expected to impair creativity, as they tax too highly the limited cognitive resources necessary for creativity”. Van Dyne and his co-authors' [11] empirical study found, work-related Stress is significantly negatively related to employee creativity. However, "arousal based theories suggest a positive relationship, in that stressors create both a demand for creativity and the motivational arousal to respond [28]". Activation theory suggests a curvilinear relationship between stress and creativity [29]. A recent meta-analysis [30] found that there was a curvilinear relationship between evaluative stress and creativity, such that low evaluative 
contexts increased creative performance over control conditions, whereas highly evaluative contexts decreased creative performance.

As in hypotheses 2, the work-related stress we are talking about is caused by job insecurity, that is, hindrance-oriented work-related stress. Some researchers found hindrance stressors (e.g. job insecurity) consistently impaired creativity [10, 23]. Thus, we hypothesize:

Hypothesis 3a: Work-related stress is negatively related to employee creativity.

Logically, job insecurity causes work-related stress (as in hypothesis 2) and work-related stress has effects on employee creativity (hypothesis 3a). Thus, we hypothesize:

Hypothesis 3b: Work-related stress will partially mediate the relationship between job insecurity and employee creativity.

\section{Proactive personality as a moderator moderates the mediation relationship of job insecurity and employee creativity via work-related stress}

As limited to personality trait, proactive personality describes a behavioral tendency to identify opportunities to change things at work and to act on those impulses [12, 13]. Employees with proactive personality are more change-oriented and self-initiated, they prefer not to passively wait for information and opportunities to come to them [12, 13, 14].

In order to accomplish their goals, proactive employees are more likely to actively shape and manipulate the environment compared to more passive workers [13, 31, 32]. To them, it is much easier to accept new ideas for improving work processes, update their working skills, and seek to better understand company politics [32, 33].

As in hypothesis 3a and 3b, work-related stress negatively related to employee creativity, work-related stress partially mediates the relationship between job insecurity and employee creativity. Employees with proactive personality attributes tended to use cognitive redefinition [14, 34]. When face stress, they will challenge it instead of avoidance [35, 36, 14]. To some employees, stress is considered as their friends. Employees with proactive personality may create positive outcomes when he or she is working in the stressed situation [14]. Thus, we predict:

Hypothesis 4: Proactive personality will moderate the strength of the mediated relationship between job insecurity and employee creativity via work-related stress, such that this mediating effect is weaker under employee with high proactive personality than under employee with low proactive personality.

\section{Team climate for innovation and employee creativity}

Cultural and social context of a firm could have an important influence on the innovation capability for its employees. When work is perceived as meaningful and motivational in an enterprise, cultural ideals, values, norms and traditions of the enterprise may elicit individual entrepreneurship actions [37]. Some researchers argue that culture is one of the most common impediments to innovation [38]. Furthermore, entrepreneurship culture has an indirect influence on employee creativity and product innovation [38].

Therefore, as the leading culture that influences employees, team climate for innovation encourages both leaders and employees. Team climate for innovation inspires positive emotions. Positive emotions broaden people's thought-action repertoires and build their enduring personal resources ranging from physical and intellectual to social and psychological resources [39, 38]. When team climate and norms encourage employees to view creativity and innovation as salient values, leader identification will be more directly channeled to creative activities [38], and employees will be encouraged to take risks and persist with challenges and try new approaches, explore uncertain but potentially promising methods and also persevere in problem solving activities [40,38].

Moreover, a climate encouraging innovation promotes the importance of such activities. Leaders will be increasingly motivated to invest their efforts towards creativity stimulating practices. According to the data correlation that Yoshida and his co-authors [41] reported, support for innovation in team is positively related to employee creativity. 
In contrast, if team norms and the context do not encourage creativity and innovation, but just place performance outcomes such as efficiency and reliability as their sole goal and punish or ignore those who try new methods [42], employees will follow the rule and not try to figure out new methods to accomplish their work. That is to say, where team climates for innovation are low or when innovation is discouraged, identification is unlikely to foster creative outcomes. Thus, we hypothesize:

Hypothesis 5: Team climate for innovation positively related to employee creativity.

\section{Team climate for innovation moderated the relationship of job insecurity and employee creativity}

From hypothesis 1, we know that job insecurity is negatively related to employee creativity. Meanwhile, from hypothesis 5, we know that team climate for innovation is positively related to employee creativity. Some researchers like Van Dyne and his co-authors claimed that innovation culture may change the impair relationship between job insecurity and employee creativity. That is to say, when team climate for innovation is low, leader identification will display a weak or negligible association with creativity [38]. Therefore, team climate for innovation has an impact on the relationship between job insecurity and employee creativity. Thus, we hypothesize:

Hypothesis 6: Team climate for innovation will moderate the negative relationship between job insecurity and employee creativity, such that the negative relationship will be weaker when team climate for innovation is high and the negative relationship will be stronger when team climate for innovation is low.

\section{Managerial Implications}

Every enterprise wants employees with high potential of creativity for it is beneficial to them. While job insecurity is a problem to nearly all employees, it is harmful to employee creativity for its leading to stress and counterproductive work behavior. Our paper tries to tell both employees and the enterprises the way to reducing the harmful effect of job insecurity and stress. Employees should learn to become proactive persons especially when facing job insecurity and stress. To the enterprises, if they want to keep their employees creative, they should create an innovation climate.

\section{References}

[1] T.M. Amabile, A model of creativity and innovation in organizations, in: B.M. Staw, L.L. Cummings (Eds.), Research in Organizational Behavior, Greenwich, CT: JAI Press, 10, 1988, pp. 123-167.

[2] N. Madjar, G.R. Oldham, M.G. Pratt, There's no place like home? The contributions of work and nonwork creativity support to employees' creative performance, Academy of Management Journal. 45 (2002) 757-767.

[3] C.E. Shalley, L.L. Gilson, T.C. Blum, Matching creativity requirements and the work environment: Effects on satisfaction and intentions to leave, Academy of Management Journal. 43 (2000) 215-223.

[4] J. Zhou, C.E. Shalley, Research on employee creativity: A critical review and directions for future research, Research in Personnel and Human Resources Management. 22 (2003) 165-217.

[5] L.Y. Sun, Z. Zhang, J. Qi, Z.X. Chen. Empowerment and creativity: A cross-level investigation, The Leadership Quarterly. 23 (2012) 55-65.

[6] J.A. Thompson, Proactive personality and job performance: A social capital perspective, Journal of Applied Psychology. 90 (2005) 1011-1017.

[7] Y. Zhang, L. Long, Effects of person-job fit and job insecurity on employees' creativity: Test of a mediated moderator model, Nankai Review. 16 (2013) 16-25. 
[8] T.M. Amabile, Motivating creativity in organizations: On doing what you love and loving what you do, California Management Review. 40 (1997) 39-58.

[9] D.K. Simonton, Origins of genius: Darwinian perspectives on creativity, Oxford University Press, Oxford, 1999.

[10] T.M. Probst, S.M. Stewart, M.L. Gruys, B.W. Tierney, Productivity, counterproductivity and creativity: The ups and downs of job insecurity, Journal of Occupational and Organizational Psychology. 80 (2007) 479-497.

[11]L. Van Dyne, K. Jehn, A. Cummings, Differential effects of strain on two forms of work performance: Individual employee sales and creativity, Journal of Organizational Behavior. 23 (2002) 57-74.

[12] J.M. Crant, Proactive behavior in organizations, Journal of Management. 26 (2000) 435-462.

[13] N. Li, J. Liang, J.M. Crant, The role of proactive personality in job satisfaction and organizational citizenship behavior: A relational perspective, Journal of Applied Psychology. 95 (2010) 395-404.

[14]G.H. Huang, H.H. Zhao, X.Y. Niu, S.J. Ashford, Reducing job insecurity and increasing performance ratings: Does impression management matter?, Journal of Applied Psychology. 98 (2013) 852-862.

[15]L. Greenhalgh, Z. Rosenblatt, Job insecurity: Toward conceptual clarity, Academy of Management Review. 9 (1984) 438-448.

[16] Q. Tian, L. Zhang, W. Zou, Job insecurity and counterproductive behavior of casino dealers - the mediating role of affective commitment and moderating role of supervisor support, International Journal of Hospitality Management. 40 (2014) 29-36.

[17] C.M. Ford, A theory of individual creative action in multiple social domains, Academy of Management Review. 21 (1996) 1112-1142.

[18]R.S. Schuler, Definition and conceptualization of stress in organizations, Organizational Behavior and Human Performance. 25 (1980) 184-215.

[19] C.L. Cooper, P.J. Dewe, M.P. O’Driscoll, Organizational stress: A review and critique of theory, research, and applications. London, 2001, 159-186.

[20] M.A. Cavanaugh, W.R. Boswell, M.V. Roehling, J.W. Boudreau, An empirical examination of self-reported work stress among US managers, Journal of Applied Psychology. 85 (2000) 65-74.

[21] R. Talbot, C. Cooper, S. Barrow, Creativity and stress, Creativity and Innovation Management. 1 (1992) 183-193.

[22] C.L. Stamper, M.C. Johlke, The impact of perceived organizational support on the relationship between boundary spanner role stress and work outcomes, Journal of Management. 29 (2003) 569-588.

[23] A.H. Hon, W.W. Chan, L. Lu, Overcoming work-related stress and promoting employee creativity in hotel industry: The role of task feedback from supervisor, International Journal of Hospitality Management. 33 (2013) 416-424.

[24] G.H. Ironson, Job stress and health, in: C.J. Cranny, P.C. Smith, E.F. Stone (Eds.), Job Satisfaction: How People Feel about Their Jobs and How It Affects Their Performance. New York, Lexington Books, 1992, pp. 235-237.

[25] J. Brockner, M. Konovsky, R. Cooper-Schneider, R. Folger, C. Martin, R.J. Bies, Interactive effects of procedural justice and outcome negativity on victims and survivors of job loss, Academy of Management Journal. 37 (1994) 397-409. 
[26] D.A. Jacobson, Personological study of the job insecurity experience, Social Behavior. 2 (1987) 143-155.

[27] R.P. Vecchio, Theoretical and empirical examination of cognitive resource theory, Journal of Applied Psychology. 75 (1990) 141-147.

[28] C.A. Sacramento, D. Fay, M.A. West, Workplace duties or opportunities? Challenge stressors, regulatory focus, and creativity, Organizational Behavior and Human Decision Processes. 121 (2013) 141-157.

[29] D.G. Gardner, Activation theory and task design: An empirical test of several new predictions, Journal of Applied Psychology. 71 (1986) 411-418.

[30]K. Byron, S. Khazanchi, D. Nazarian, The relationship between stressors and creativity: A meta-analysis examining competing theoretical models, Journal of Applied Psychology. 95 (2010) 201-212.

[31] B. Erdogan, T.N. Bauer, Enhancing career benefits of employee proactive personality: The role of fit with jobs and organizations, Personnel Psychology. 58 (2005) 859-891.

[32] G.J. Greguras, J.M. Diefendorff, Why does proactive personality predict employee life satisfaction and work behaviors? A field investigation of the mediating role of the self-concordance model, Personnel Psychology. 63 (2010) 539-560.

[33] S.E. Seibert, J.M. Crant, M.L. Kraimer, Proactive personality and career success, Journal of Applied Psychology. 84 (1999) 416-427.

[34] S. E. Seibert, M.L. Kraimer, J.M. Crant, What do proactive people do? A longitudinal model linking proactive personality and career success, Personnel psychology. 54 (2001) 845-874.

[35]D.G. Allen, K.P. Weeks, K.R. Moffitt, Turnover intentions and voluntary turnover: The moderating roles of self-monitoring, locus of control, proactive personality, and risk aversion, Journal of Applied Psychology. 90 (2005) 980-990.

[36]D. Chan, Interactive effects of situational judgment effectiveness and proactive personality on work perceptions and work outcomes, Journal of Applied Psychology. 91 (2006) 475-481.

[37]H. Menzel, I. Aaltio, J. Ulijn, On the way to creativity: Engineers as intrapreneurs in organizations, Technovation. 27 (2007) 732-743.

[38] G. Martín-de Castro, M. Delgado-Verde, J.E. Navas-López, J. Cruz-González, The moderating role of innovation culture in the relationship between knowledge assets and product innovation, Technological Forecasting and Social Change. 80 (2013) 351-363.

[39]B.L. Fredrickson, C. Branigan, Positive emotions broaden the scope of attention and thought-action repertoires, Cognition and Emotion. 19 (2005) 313-332.

[40] M. Baer, G.R. Oldham, The curvilinear relation between experienced creative time pressure and creativity: moderating effects of openness to experience and support for creativity, Journal of Applied Psychology. 91 (2006) 963-970.

[41]D.T. Yoshida, S. Sendjaya, G. Hirst, B. Cooper, Does servant leadership foster creativity and innovation? A multi-level mediation study of identification and prototypicality, Journal of Business Research. 67 (2014) 1395-1404.

[42] G. Hirst, R. Van Dick, D. Van Knippenberg, A social identity perspective on leadership and employee creativity, Journal of Organizational Behavior. 30 (2009) 963-982. 